\title{
Computed tomography-guided percutaneous ozone injection of the Gasserian ganglion for the treatment of trigeminal neuralgia
}

This article was published in the following Dove Press journal: Journal of Pain Research

\author{
Jian-Xiong $A n^{1,2}$ \\ Hui Liu' \\ Ruo-Wen Chen ${ }^{1,2}$ \\ Yong Wang' \\ Wen-Xing Zhao' \\ Derek Eastwood ${ }^{3}$ \\ John P Williams ${ }^{4}$
}

'Department of Anesthesiology, Pain Medicine \& Critical Care Medicine, Aviation General Hospital of China Medical University \& Beijing Institute of Translational Medicine, Chinese Academy of Sciences, ${ }^{2}$ Department of Anesthesiology, Weifang Medical University, Beijing, People's Republic of China; ${ }^{3}$ Department of Pain Services, Wirral University Teaching Hospital, Wirral, Merseyside, UK; ${ }^{4}$ Department of Anesthesiology, University of Pittsburgh School of Medicine, Pittsburgh, PA, USA
Correspondence: Ruo-Wen Chen Department of Anesthesiology, Pain Medicine and Critical Medicine, Aviation General Hospital of China Medical University, Beiyuan Road 3\#, Beijing 1000 12, People's Republic of China $\mathrm{Tel}+86 \quad 15801$ I 8332 I Fax +86 I0 59520393 Email wotaoyanjiaobu@।63.com
Objective: The aim of this study was to evaluate the therapeutic effect of computed tomography (CT)-guided percutaneous ozone injection for refractory trigeminal neuralgia.

Design: A retrospective evaluation was performed in the study.

Setting: The study was conducted at a university hospital pain center.

Patients and methods: A total of 29 patients with a clinical diagnosis of refractory trigeminal neuralgia were enrolled. All patients were treated with a percutaneous ozone injection and one patient was excluded. There were 21 patients with classical trigeminal neuralgia (group A) and seven patients with painful trigeminal neuropathy caused by post-herpetic neuralgia (group B). The percutaneous injection was an oxygen-ozone mixture at an ozone concentration of $30 \mu \mathrm{g} / \mathrm{mL}$ into the Gasserian ganglion performed under CT guidance. The number of procedures performed varied from one to as many as 16 . Outcomes were evaluated using visual analog scale (VAS) pain scores.

Results: The combined VAS scores were $7.11 \pm 1.23$ pretreatment, $2.86 \pm 1.69$ posttreatment $(P<0.05)$ and $3.25 \pm 2.01$ after 6-month follow-up $(P<0.05)$. In group A, the VAS scores were $7.10 \pm 1.04$ pretreatment and $2.90 \pm 1.84$ posttreatment $(P<0.05)$. In group $\mathrm{B}$, the VAS scores were $7.14 \pm 1.77$ pretreatment and $2.71 \pm 1.25$ posttreatment $(P<0.05)$. After 6 -months follow-up, the VAS score was $3.38 \pm 2.18$ in group A and $2.86 \pm 1.46$ in group $\mathrm{B}$, a decrease compared to pretreatment $(P<0.05)$. VAS of Group A and B showed no difference not only in pretreatment but also in postreatment and follow-up.

Conclusion: Percutaneous ozone injection is a safe and effective treatment for patients with refractory trigeminal neuralgia.

Keywords: trigeminal neuralgia, percutaneous ozone injection, Gasserian ganglion

\section{Introduction}

Trigeminal neuralgia (TN) is an affliction of the face, characterized by brief electricshock-like pain limited to one or more divisions of the trigeminal nerve, commonly evoked by trivial stimuli such as shaving, talking and washing of the face but may also occur spontaneously with abrupt onset and termination. ${ }^{1}$ The prevalence ratio is 4 per 100,000 in the population, and TN commonly affects patients over 50 years, occurring more frequently in women. ${ }^{2}$ Multiple treatment options for the management of TN are available and have shown benefit in the relief of pain, ranging from simple medicines to open surgery. With conservative treatments, such as drug therapy, more than $25 \%$ patients do not obtain pain relief, and medications usually produce mildto-moderate side effects, such as dizziness..$^{3-5}$ Microvascular decompression (MVD) offers the benefit of maintaining normal facial sensation and avoiding facial numbness; 
however, there are a considerable number of patients who only receive partial pain remission or no benefit after the surgery. Furthermore, the reported annual recurrence rate is high, and some people may be less willing to accept heroic, invasive surgery. ${ }^{6}$ Apart from the treatments mentioned earlier, percutaneous radiofrequency thermocoagulation (PRT) and percutaneous retrogasserian glycerol rhizotomy (PRGR) used to be popular among patients because of the simplicity and reduced trauma compared to MVD. However, after the reports of nerve damage, many patients are unwilling to accept this interventional option. ${ }^{7,8}$ The question is how to treat patients who do not respond to conservative treatments? The management of those patients who are drug resistant, cannot tolerate the side effects and have recurrence after MVD as well as those who choose not to undergo invasive surgery or interventional procedures is challenging. At our pain center, percutaneous ozone injection has been employed since 2013 for TN. It has an effective analgesic effect with minimal trauma and fewer complications.

Over the past 3 decades, percutaneous ozone injection has been used as an effective treatment for pain relief in certain concentrations without neurologic damage. ${ }^{9}$ It has been demonstrated to be of benefit in treating low back pain from a herniated disk as well as refractory headache. ${ }^{10,11}$ Multiple mechanisms of action have been proposed to explain the mechanism of percutaneous ozone injection including antiinflammatory effects and oxidative action on proteoglycans. ${ }^{12}$ The use of percutaneous ozone injection in $\mathrm{TN}$ has not been thoroughly investigated, to date.

In this study, we retrospectively evaluated 29 patients with refractory TN. Initial percutaneous injections of ozone therapy on the Gasserian ganglion guided by computed tomography (CT) scan were evaluated for efficacy. Therapeutic effectiveness and follow-up information were obtained. Overall improvement in pain was observed, up to the 6-month follow-up. The study was designed to determine any influence of age, gender, pain duration and the number of treatments on the outcomes such as pain relief and tactile sensation after the ozone injection. We also identified subgroups of people with TN based on their etiology, and then compared the pain relief and tactile sensation of these subgroups.

\section{Patients and methods}

\section{Study design}

The study was a retrospective cohort study. Approval from the Institutional Review Board of the Aviation General Hospital of China Medical University was obtained. The approval included a waiver of informed consent, because the study did not include direct contact with the study population, and all patient identifiers were removed from the dataset on initial collection.

\section{Patient characteristics}

From February 2014 to May 2015, 29 patients with TN at our pain center were treated with percutaneous ozone injection under CT guidance. Patients with symptoms of TN with a history of failed treatment(s) or recurrence of pain were included in this study. Patients who refused to accept any kind of treatment were also included in this study because of the unacceptable side effects of therapies. Patients with severe systemic disease, cardiac or pulmonary dysfunction, and other contraindication for percutaneous ozone injection, including hyperthyroidism, favism, acute myocardial infarction and pregnancy were excluded. The flow diagram of therapeutic process is shown in Figure 1. Independent variables such as age, gender, pain duration and the number of treatments were documented.

\section{Surgical procedure}

Each patient was taken to a sterile CT examination room and placed in the supine position. A line was made between the mental protuberance and the angle of the mandible perpendicular to the CT scanner bed. Each patient's vital signs were monitored throughout the entire procedure. The puncture of Gasserian ganglion was according to the Hartel anterior route (Figure 2). Using the puncture method in an anterior approach, a metal marker was placed at a site on the lateral side of the labial angle, a site near the cheekbone above the second molars of the upper jaw. A CT location measurement of the puncture angle and the distance between the punctured skin and the foramen ovale was carried out to determine the punctured site and the puncture path (Figure 3A). Following skin sterilization, the insertion point was anesthetized with $1 \%$ lidocaine. Thereafter, a $22 \mathrm{G}$ needle $(30 \mathrm{~mm})$ was inserted with the insertion angle, and the depth to the foramen ovale determined according to the CT location measurement (Figure $3 \mathrm{~B}$ ).

In this procedure, the needle was not inserted to a deep position which is close to the subarachnoid space. When placing the needle into the foramen ovale, 64-slice spiral CT scans were used to confirm the position of the needle tip. This prevented the needle from going too deep and entering the subarachnoid space. There was no indication of cerebral spinal fluid leakage in any of the procedures which would be seen if the needle had been in the subarachnoid space. 


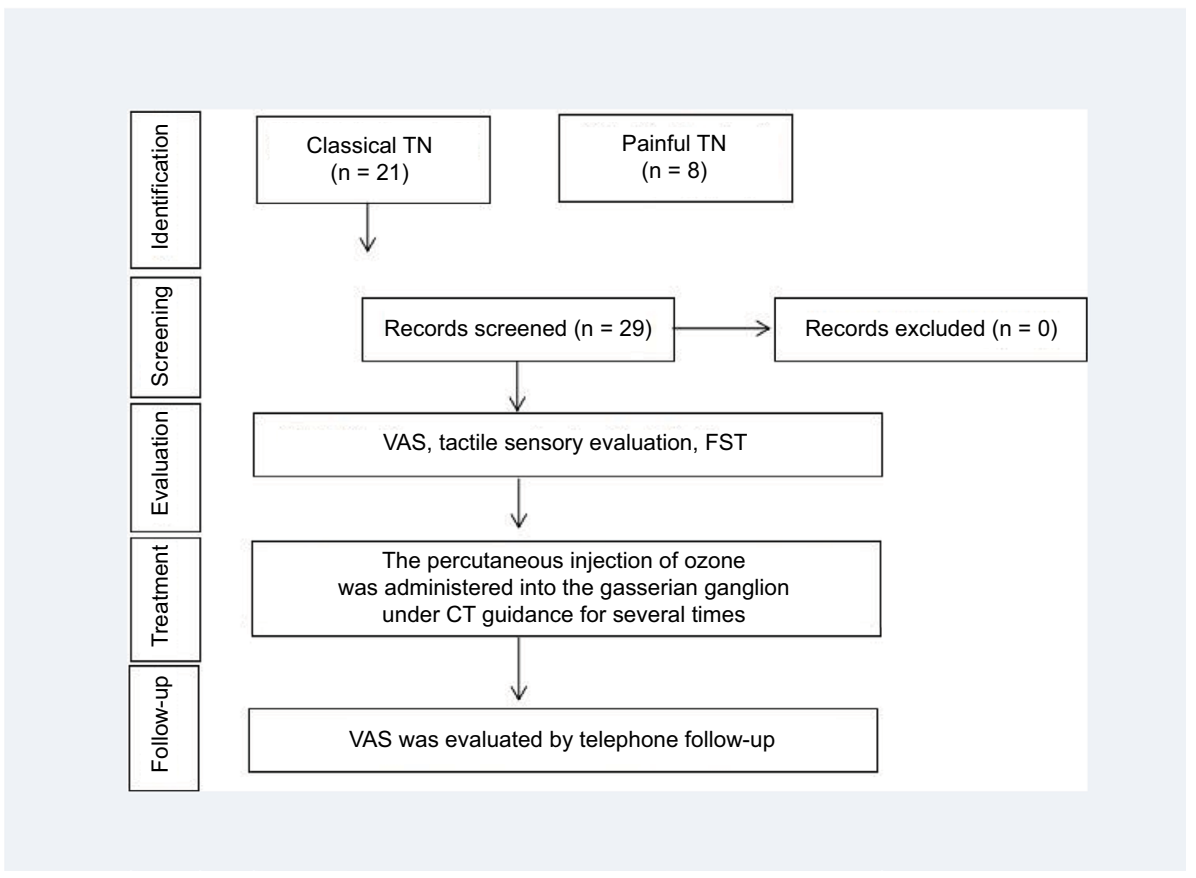

Figure I The flow diagram of therapeutic process.

Abbreviations: CT, computed tomography; FST, facial skin temperature; TN, trigeminal neuralgia; VAS, visual analog scale.

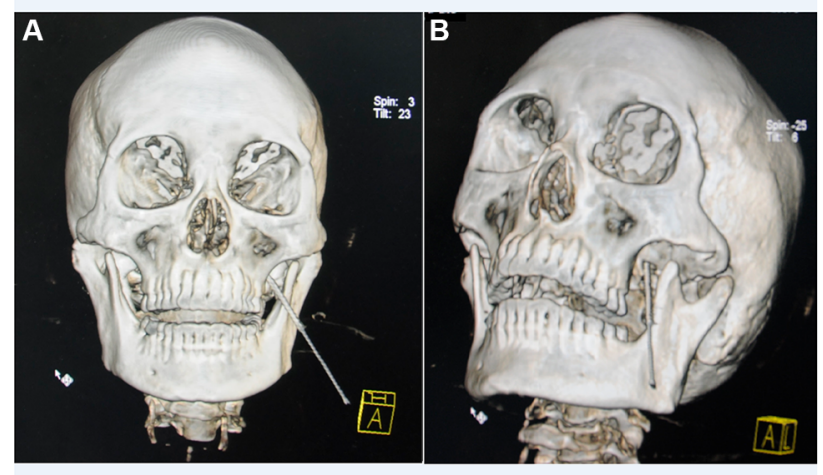

Figure $2 \mathrm{~A}$ 3D CT reconstruction showing the trajectory of the needle after insertion Notes: (A) A frontal 3D CT reconstruction image showing the position of the needle. (B) A lateral 3D CT reconstruction image showing the position of the needle in foramen rotundum.

Abbreviations: $\mathrm{CT}$, computed tomography; 3D, three-dimensional.

Previous studies have also shown that a thunderclap headache is caused by an inadvertent intrathecal puncture during oxygen-ozone therapy for lumbar disk herniation. ${ }^{13}$ However, in our cohort, no patients reported this complication not only during the procedure but also in subsequent days.

After verification, motor $(2 \mathrm{~Hz}, 1 \mathrm{~ms})$ and sensory $(50 \mathrm{~Hz}$, $0.1 \mathrm{~ms}$ ) stimulation was performed to confirm or readjust the needle tip position to confirm accuracy. After positioning, the gas mixture was injected at a concentration of $30 \mu \mathrm{g} / \mathrm{mL}$ of an $\mathrm{O}_{2}-\mathrm{O}_{3}$ mixture $(3 \mathrm{~mL})$ which was generated by the ozone therapy devices (Ozomed Basic; Kastner-Praxisbedarf $\mathrm{GmbH}$, Rastatt, Germany). No steroids were injected after ozone injection. All patients remained under the care of our

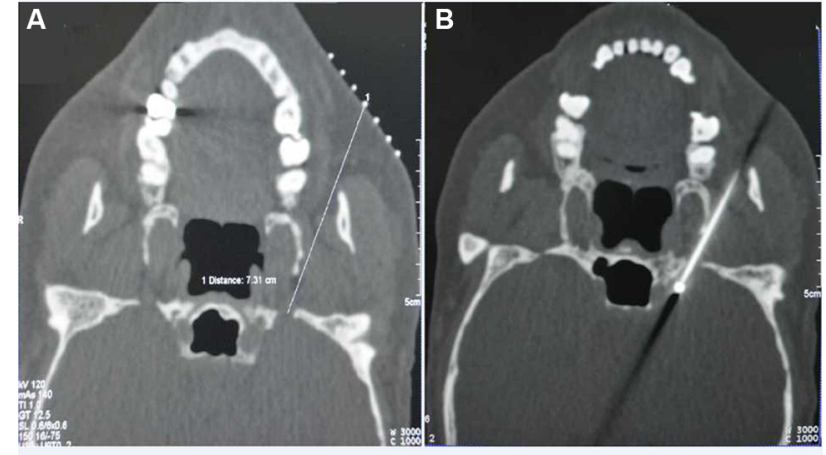

Figure 3 Puncture at foramen ovale performed under CT guidance. Notes: (A) A horizontal CT image showing the distance between the punctured skin and the foramen ovale. (B) A horizontal CT image showing the position of the needle in foramen ovale.

Abbreviation: CT, computed tomography.

pain clinic for a period of time that varied from a few hours to many weeks. The number of procedures performed varied from one to as many as 16 until the patient reported high satisfaction with pain relief. In our pain center, patients who did not achieve immediate and satisfying pain relief would undergo a second procedure.

\section{Assessment of pain reduction}

The visual analog scale (VAS), a widely used metric scale for measuring pain, was completed by patients both pre- and immediately postoperatively. Patients were shown a horizontal line marked from 0 (no pain) to 10 (most severe pain) and asked to rank the severity of their pain. A difference of at least 
$3 \mathrm{~cm}$ of VAS score was considered clinically significant. ${ }^{14}$ This assessment process was performed by nursing personnel who were not involved in the clinical procedure.

\section{Follow-up}

Patients were recalled for follow-up clinical visits 6 months after the last treatment. During the telephone follow-up, an evaluation of pain using a VAS was conducted. Follow-up interviews were performed by nursing personnel who were not involved in the clinical procedure and the assessment process after the last injection.

\section{Tactile sensory evaluation}

Testing was performed in a quiet area with the patient's vision occluded by asking them to close their eyes. Evaluation of the tactile sensation of the face was performed in six regions (the three branches of the trigeminal nerve bilaterally). A series of calibrated von Frey hairs (Stoelting, Chicago, IL, USA) with stiffness $0.008 \mathrm{~g} / \mathrm{mm}^{2}$ were applied perpendicular to facial surface. The von Frey data were recorded when the patients responded to the stimulus by saying "yes." If the patients did not respond to the stimulus, the next largest monofilament was selected, and the process was repeated. The test was performed before the first treatment and immediately after the final treatment.

\section{Facial skin temperature (FST)}

The room temperature was maintained at $23^{\circ} \mathrm{C}$ by central air conditioning. A noncontact infrared thermometer (NCIT) was used (Berrcom, model JTB183 ${ }^{\circledR}$, Guangzhou, China) to measure FST from $32^{\circ} \mathrm{C}$ up to $42.9^{\circ} \mathrm{C}$. The measurement was obtained on the body surface of the patients, on the six areas (the three branches of the trigeminal nerve bilaterally), and the changes in the FST (data not shown) were recorded before and after the treatment. During measurements, the sensor was placed $3.0 \mathrm{~cm}$ from the facial skin. To avoid one single measurement resulting in outliers, three consecutive measurements were taken from each of the aforementioned areas. The same researcher performed all measurements. The evaluation was performed before and after the final treatment.

\section{Statistical analysis}

All data collection and analyses were performed by an independent reviewer. The SPSS (version 19; IBM Corporation, Armonk, NY, USA) was used for all statistical analyses. Variables with normal distributions are presented as mean $\pm \mathrm{SD}$ and non-normally distributed variables as median and range. Comparisons of differences before and after treatment were with paired $t$-tests. Comparisons of differences between groups were with independent sample $t$-test (VAS, FST and von Frey variable). Comparisons of intra-group differences were with paired $t$-tests. Demographic and pain characteristic correlates of therapeutic effect were analyzed using univariate regression. Univariate regression analysis was performed using the $\chi^{2}$ test. Logistic regression analysis was performed to evaluate the relationship between possible outcome predictors, such as age, gender and the number of treatments, and their therapeutic effects. A $P$-value of $<0.05$ was considered to be statistically significant.

\section{Results}

Of the 29 percutaneous ozone injections performed, 28 patients met inclusion criteria; 17 (60.7\%) of injections were performed in women, and 11 (39.3\%) were performed in men. Among all 29 patients, one (3.57\%) patient was excluded because of data missing.

The mean $( \pm \mathrm{SD})$ age of patients accepting percutaneous ozone injections was $61( \pm 13.0)$ years. The mean duration of TN symptoms was 64.7 months (median: 24 months, range: 0.5-480 months). The left side of the face was affected in eight patients, whereas the right side was affected in 19 and one patient experienced bilateral symptoms. Out of 28 patients, 21 patients have refractory pain which had a recurrence after treatment or did not response to past treatments such as antiepileptic drugs, transcuataneous electricalnerve stimulation (TENS) and MVD, while seven patients without any treatment but didn't want to accept conservative treatment, MVD or PRT. There were seven patients with painful trigeminal neuropathy (group B) caused by post-herpetic neuralgia (PHN) and 21 patients with classical TN (group A) among all 28 patients in the study. Further details of pain intensity data distribution are provided in Table 1. Patient age was classified into two groups: $\leq 65$ years and $>65$ years. Pain duration was treated as a potential predictive variable and classified as acute or subacute ( $\leq 6$ months) or chronic ( $>6$ months). The number of treatments was classified as $\leq 5$ and $>5$. Age, gender and pain duration did not independently predict a clinically successful outcome $(P>0.05)$. However, the number of treatments had a significant effect on the results $(P<0.05)$. Further details are provided in Tables 2 and 3.

As shown in Figure 4A, the VAS score was $7.11 \pm 1.23$ pretreatment and $2.86 \pm 1.69$ posttreatment. Pain intensity assessed by the VAS posttreatment was significantly reduced $(P<0.05)$. In fact, 20 patients achieved immediate pain relief and three patients experienced recalcitrant symptoms after the treatment, while there was no difference in the number 


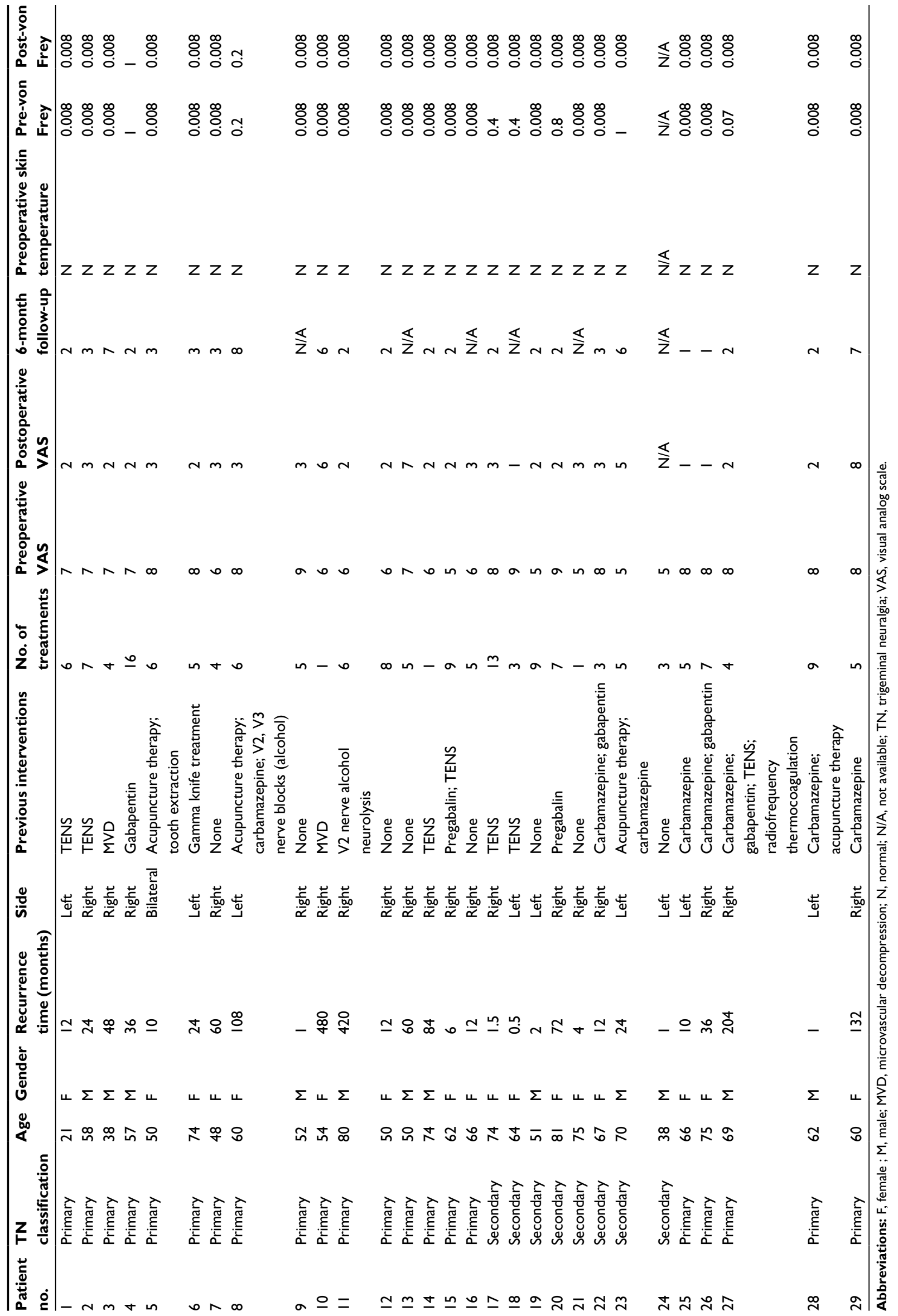


Table 2 Univariate analysis of possible outcome predictors for injection effectiveness after treatment

\begin{tabular}{|c|c|c|c|}
\hline Characteristics & Effective $(N=24)$ & $\begin{array}{l}\text { Not effective } \\
(\mathrm{N}=4)\end{array}$ & $P$-value \\
\hline Age (years) & & & 0.353 \\
\hline$<65$ & II (84.6\%) & $2(15.4 \%)$ & \\
\hline$>65$ & $9(90.0 \%)$ & I (10.0\%) & \\
\hline Gender & & & 0.636 \\
\hline Male & $9(75.0 \%)$ & $3(25.0 \%)$ & \\
\hline Female & 15 (93.8\%) & I (6.25\%) & \\
\hline Pain duration & & & 1.00 \\
\hline$\leq 6$ months & $6(100 \%)$ & $0(0 \%)$ & \\
\hline$>6$ months & $18(81.8 \%)$ & $4(18.2 \%)$ & \\
\hline Number of treatments & & & 0.044 \\
\hline$\leq 5$ & II (73.3\%) & $4(16.0 \%)$ & \\
\hline$>5$ & $13(100 \%)$ & $0(0 \%)$ & \\
\hline
\end{tabular}

Table 3 Multiple logistic regression analysis of possible outcome predictors for injection effectiveness after treatment

\begin{tabular}{llll}
\hline Characteristics & OR & $\mathbf{9 5 \% ~ C l}$ & P-value \\
\hline Age & 15.9 & $0.618-407$ & 0.095 \\
Gender & 1.68 & $0.102-27.7$ & 0.716 \\
Pain duration & 0.711 & $0.028-17.8$ & 0.836 \\
Number of treatments & I.47E9 & I.47E9-I.47E9 & 0.003 \\
\hline
\end{tabular}

Abbreviations: $\mathrm{Cl}$, confidence interval; $\mathrm{OR}$, odds ratio. of treatments $(P>0.05)$. As shown in Figure $4 \mathrm{~B}$, in group A, the VAS score was $7.10 \pm 1.04$ pretreatment and $2.90 \pm$ 1.84 posttreatment. In group B, the preoperative VAS score was $7.14 \pm 1.77$ and the postoperative VAS score was 2.71 \pm 1.25 . Pain intensity assessed by the VAS posttreatment was reduced compared to the pretreatment in both groups $(P<0.05)$. The difference in the VAS scores between these two groups was statistically insignificant not only before the treatment but also after the treatment $(P>0.05)$. In other words, there were 24 patients with pain relief and only four did not respond to the treatment. In addition, out of 21 patients with no response to any kind of treatment before, 18 patients had pain relief after treatment and three patients had no improvement.

Patients were followed up at 6 months posttreatment. As shown in Figure 4A, the follow-up VAS score was $3.25 \pm$ 2.01. Pain intensity assessed by the VAS at the 6-month follow-up was significantly reduced compared to the pretreatment $(P<0.05)$. Recurrence was observed in two patients at follow-up. As shown in Figure 4B, in group A, the follow-up VAS score was $3.38 \pm 2.18$. In group $\mathrm{B}$,

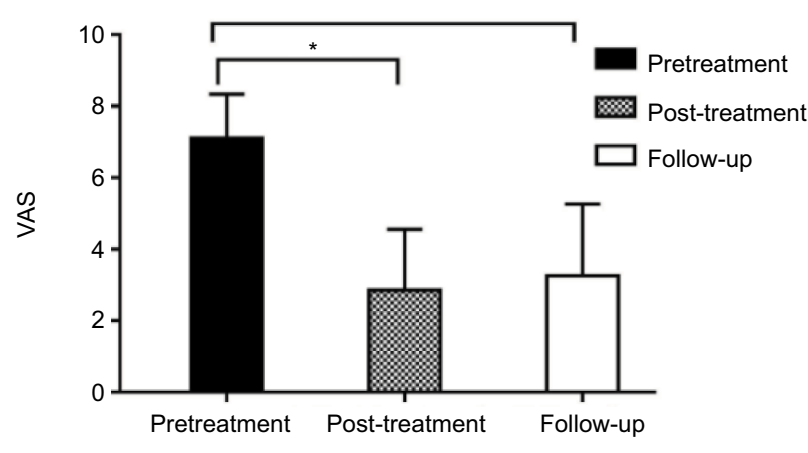

C

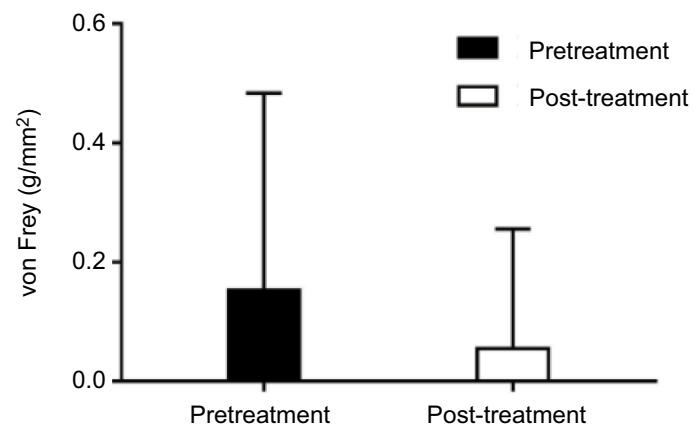

B
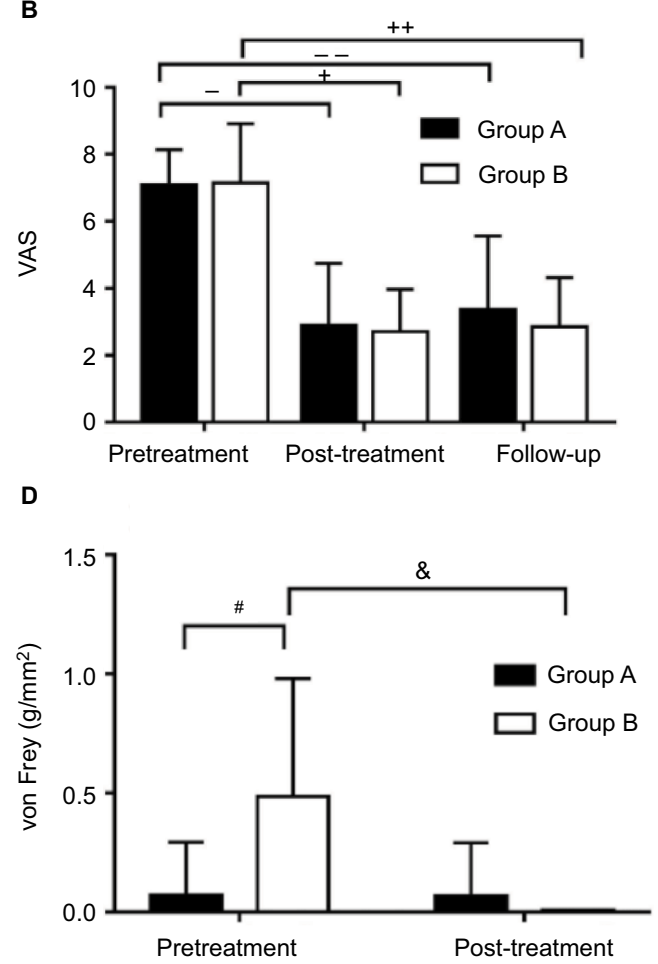

Figure 4 VAS and von Frey of patients in different periods.

Notes: (A and B) Evolution of pain intensity: the pain intensity assessed by the VAS before ozone therapy (pretreatment), after ozone therapy (post-treatment) and at 6-month follow-up (follow-up). Values are presented as mean \pm SD. (A) There was a significant decrease in pain intensity $(* P<0.05)$ after the ozone therapy, and this was maintained even up to 6 months of the follow-up $(* * P<0.05)$. (B) There was a significant decrease in pain intensity after the ozone therapy in both groups $(-+P<0.05)$, and this was even maintained for up to 6 months of the follow-up $\left({ }^{-,++}+P<0.05\right)$. However there were no differences between these two groups at any time point $(P>0.05)$. (C and $\left.\mathbf{D}\right)$ Evolution of tactile detections: the tactile intensity assessed by the von Frey before ozone therapy (pretreatment), after ozone therapy (post-treatment). Values are presented as mean \pm SD. (C) There was no difference in von Frey $(P>0.05)$ before and after the ozone therapy. (D) No difference was found in von Frey of group A before and after the treatment $(P>0.05)$, while there was a significant decrease in von Frey $\left({ }^{\&} P<0.05\right)$ of group $B$ after the ozone therapy. Moreover the pretreatment von Frey of group $B$ was significantly higher compared to group $A(\# P<0.05)$, but no difference was observed between these two groups after the therapy $(P>0.05)$.

Abbreviation: VAS, visual analog scale. 
the follow-up VAS score was $2.86 \pm 1.46$. Pain intensity assessed by the VAS at the 6-month follow-up was significantly reduced compared to the pretreatment in both groups $(P<0.05)$. There were no significant differences in the follow-up VAS scores between these two groups $(P>0.05)$. Interestingly, two patients in group A had pain recurrence at the 6-month follow-up, but patients in group B did not. Further details of the pain intensity data distribution are depicted in Figure 4B.

No complications, such as abnormal FST or facial tactile loss, were observed in any patients after the surgery. As shown in Figure 4C, the von Frey was $0.153 \pm 0.330 \mathrm{~g} / \mathrm{mm}^{2}$ pretreatment and $0.0554 \pm 0.200 \mathrm{~g} / \mathrm{mm}^{2}$ posttreatment. There were no differences in von Frey before and after the treatment $(P>0.05)$. As shown in Figure 4D, the von Frey in group A was $0.0707 \pm 0.224 \mathrm{~g} / \mathrm{mm}^{2}$ pretreatment and $0.0652 \pm$ $0.224 \mathrm{~g} / \mathrm{mm}^{2}$ posttreatment. Tactile detections assessed by the von Frey pre- and post-treatment showed no difference $(P>0.05)$. In group $\mathrm{B}$, the von Frey was $0.486 \pm 0.495 \mathrm{~g} / \mathrm{mm}^{2}$ pretreatment and $0.008 \pm 0.000 \mathrm{~g} / \mathrm{mm}^{2}$ posttreatment. Tactile detections assessed by the von Frey posttreatment were reduced compared to the pretreatment $(P<0.05)$. Before treatment, when compared to group A, the von Frey test in group B was clearly higher $(P<0.05)$, but there was no difference between these two groups after the treatment $(P>0.05)$.

Complications included transient facial numbness (60\%), blurred vision (22\%) and dizziness (14\%) because of the usage of local anesthesia. After half an hour, all these symptoms were relieved.

\section{Discussion}

This is the first time that percutaneous ozone injection treatment has been reported in a series of patients with refractory TN. In our study, pain intensity assessed by a VAS score pre and posttreatment was significantly reduced $(P<0.05)$. Moreover, a lower VAS score was also observed at 6-month of follow-up compared to the pretreatment $(P<0.05)$. However, VAS scores in the two groups showed no difference at every time point $(P>0.05)$. Gender, age and pain duration were not significant prognostic factors for the treatment effectiveness in this study. But the number of treatments independently predicted a clinically successful outcome and had a significant effect on the results. Of the 21 patients who previously did not respond to treatment such as antiepileptic drugs and MVD, 18 achieved immediate pain relief after treatment with ozone. Our results suggest that CT-guided percutaneous ozone injection procedure is an effective therapy, especially for patients with refractory $\mathrm{TN}$ who do not obtain pain relief or have a post-treatment recurrence after conventional therapy or surgical treatment.

The analgesic mechanism of percutaneous ozone injection in TN was still unclear. One possible mechanism is attributed to its anti-inflammatory effects. First, the ozone injected proximal to the ganglion was believed to result in an increase in superoxide dismutase production and a reduction in reactive oxygen species to reduce or prevent cell injury. ${ }^{15,16}$ Second, previous studies showed that ozone injection increases the release of antagonists that are able to neutralize pro-inflammatory cytokines such as interleukin (IL)-1, IL-2, IL-8, IL-12, IL-15, interferon- $\alpha$ and tumor necrosis factor- $\alpha .{ }^{17}$ Third, ozone could directly inhibit the synthesis of pro-inflammatory prostaglandins and the release of bradykinin. ${ }^{18}$ According to previous studies, we supposed that chronic pain is related to chronic inflammation. Thus, it was likely that the anti-inflammatory effect of ozone may be the main mediating factor. In this study, we drew an interesting conclusion that the number of treatments had a significant effect on the results $(P<0.05)$. In this case, we hypothesized that ozone therapy decreased the inflammation through decreasing concentrations of various proinflammatory cytokines, but anti-inflammation reaction happened only after a certain time, not immediately. The processing of the anti-inflammation reaction is long running. Moreover, previous studies showed convincing evidence of demyelination on pain model of animals. So, we believed that pain would be remarkably relieved after the demyelinated nerve repair induced by ozone and, of course, it must be a long-running process. Actually, a number of studies showed that ozone is a pro-inflammatory mediator or resulted in nerve damage. ${ }^{19,20}$ However, in our opinion, ozone had a hormetic profile - low doses are therapeutic and high doses are toxic.

Another possible mechanism of ozone-induced pain relief could be increasing release of endorphins. ${ }^{12}$ Ozone injection resulted in the stimulation of the enkephalinergic interneuron to release endorphins. Endorphins inhibited the presynaptic connection of other neurocytes that stimulate the release of substance $\mathrm{P}$, resulting in inhibition of pain signaling to the thalamus and cortex. Finally, ozone exposure might improve the production and release of vasoactive factors producing a vasodilatory effect and preventing thrombogenesis. Recently, Valacchi and Bocci ${ }^{21}$ found that there was an enhanced production of nitric oxide by human endothelial cells after 20 min of incubation in ozonated serum. Moreover, localized 
oxygenation, via vasodilation, may favor oxidation of lactate and reduction in acidosis.

In this study, four out of 28 patients reported no response to percutaneous ozone injection. They received the same concentrations of $\mathrm{O}_{2}-\mathrm{O}_{3}$ mixture. It was possible the failure of response in those patients was related to anatomical variation and poor access to the Gasserian ganglion. In addition, two out of 21 patients with classical $\mathrm{TN}$ in group A had pain recurrence at 6-month follow-up, while the remaining patients with $\mathrm{PHN}$ did not. While there was no difference in the concentrations of $\mathrm{O}_{2}-\mathrm{O}_{3}$ mixture, an assumption could be made that the analgesic effect in patients with PHN was probably due to the direct effect on the virally damaged tissue.

The cause of the classical TN was still unknown. While percutaneous ozone injections reduced inflammation, the mechanism of effect was still not understood. Ozone injections could ease the pain but are not a cure as witnessed by recurrence at 6 months after treatment.

This study evaluated the facial tactile sensitivity of TN patients and observed abnormalities on tactile thresholds on the affected side in patients with PHN (group B). At the affected side, von Frey sensitivity was decreased and restored to normal after percutaneous ozone injection $(P$ $<0.05)$. We suggested that the healing of damaged nerves, induced by improving oxygen delivery coupled with an antiinflammatory action, is an effect of ozone. Normal facial tactile sensation was maintained, and facial numbness was avoided. We considered that it is also because of ozone's anti-inflammatory effects instead of trigeminal neurectomy. We believed that this technique is a good treatment choice for TN patients rather than PRT or PRGR and other invasive surgeries. No mortality or other life-threatening complications were observed.

There were several limitations in this study. First, this study was retrospective in design. Out of 28 charts reviewed, clinical records were incomplete with data missing in one case $(3.57 \%)$ during therapy and follow-up period. Second, a large-scale longitudinal prospective study would confirm the validity of our findings. Third, follow-up time was limited to 6 months and was relatively short. Moreover, researchers could not control for other treatments such as TENS and physical therapy during follow-up. These treatments might have influenced the results of this study. Finally, contrast medium injected at the site of the procedure might have provided further validation of correct needle placement, but it may also have interfered with the therapy itself.

\section{Conclusion}

This study suggested that age, gender, pain duration and the number of treatments were not associated with, or predictive of, a poor outcome of CT-guided percutaneous ozone injection. Assessment of these clinical factors did not have to be incorporated into the evaluation and counseling of patients with TN who were candidates for CT-guided percutaneous ozone injection. In the light of other current therapies for TN, percutaneous ozone injection had some advantages. First, this kind of therapy was effective. It had been used to treat patients with recurrent pain after MVD and drug resistance who did not respond to conservative treatment, having less side effects than the traditional antiepileptic drugs. Second, it was a non-oral therapy for patients who cannot take oral medications because their pain intensity is aggravated with mouth opening. Third, compared to interventional therapy, there were no serious adverse reactions such as nerve damage.

\section{Acknowledgment}

This study was supported by the Capital Foundation of Medical Developments (CFMD) (grant no. 2014-3-6101).

\section{Disclosure}

The authors report no conflicts of interest in this work.

\section{References}

1. Merskey H, Bogduk N. Classification of Chronic Pain: Descriptions of Chronic Pain Syndromes and Definitions of Pain Terms. 2nd ed. IASP, Seattle. 1994;59-71.

2. Krafft RM. Trigeminal neuralgia. Am Fam Physician. 2008;77(9): 1291-1296.

3. Katusic S, Williams DB, Beard CM, Bergstralh EJ, Kurland LT. Epidemiology and clinical features of idiopathic trigeminal neuralgia and glossopharyngeal neuralgia: similarities and differences, Rochester, Minnesota, 1945-1984. Neuroepidemiology. 1991;10(5-6):276-281.

4. Luo F, An JX, Fan BF, Han JS. Treatment of trigeminal neuralgia with transcutaneous electric acupoint stimulation on twenty-eight patients. Chin J Pain Med. 1997;3:107-111.

5. Chen RW, Liu H, An JX, et al. Cognitive effects of electro acupuncture and pregabalin in a trigeminal neuralgia rat model induced by cobra venom. J Pain Res. 2017;10:1887-1897.

6. Lai GH, Tang YZ, Wang XP, Qin HJ, Ni JX. CT-guided percutaneous radiofrequency thermocoagulation for recurrent trigeminal neuralgia after microvascular decompression: a cohort study. Medicine (Baltimore). 2015;94(32):e1176.

7. Kosugi S, Shiotani M, Otsuka Y, et al. Long-term outcomes of percutaneous radiofrequency thermocoagulation of Gasserian ganglion for 2nd- and multiple-division trigeminal neuralgia. Pain Pract. 2015;15(3):223-228.

8. Huang FB, Yao M, Feng Z, et al. CT-guided percutaneous infrazygomatic radiofrequency neurolysis through foramen rotundum to treat $\mathrm{V} 2$ trigeminal neuralgia. Pain Med. 2014;15(8):1418-1428.

9. Lin Q, Chen H, Lu C, et al. Effects of ozone on sciatic nerve in rat. Interv Neuroradiol. 2011;17(3):281-285. 
10. Magalhaes FN, Dotta L, Sasse A, Teixera MJ, Fonoff ET. Ozone therapy as a treatment for low back pain secondary to herniated disc: a systematic review and meta-analysis of randomized controlled trials. Pain Physician. 2012;15(2):E115-E129.

11. Clavo B, Santana-Rodriguez N, Gutierrez D, et al. Long-term improvement in refractory headache following ozone therapy. J Altern Complement Med. 2013;19(5):453-458.

12. Bocci V, Borrelli E, Zanardi I, Travagli V. The usefulness of ozone treatment in spinal pain. Drug Des Devel Ther. 2015;9:2677-2685.

13. Devetag Chalaupka F, Caneve G, Mauri M, Zaiotti G. Thunderclap headache caused by minimally invasive medical procedures: description of 2 cases. Headache. 2007;47(2):293-295.

14. Kanai A, Suzuki A, Kobayashi M, Hoka S. Intranasal lidocaine $8 \%$ spray for second-division trigeminal neuralgia. Br J Anaesth. 2006;97(4):559-563.

15. Bocci V. Does ozone therapy normalize the cellular redox balance? Implications for therapy of human immunodeficiency virus infection and several other diseases. Med Hypotheses. 1996;46(2):150-154.
16. Bonetti M, Fontana A, Albertini F. CT-guided oxygen-ozone treatment for first degree spondylolisthesis and spondylolysis. Acta Neurochir Suppl. 2005;92:87-92.

17. Andreula CF, Simonetti L, De Santis F, Agati R, Ricci R, Leonardi M. Minimally invasive oxygen-ozone therapy for lumbar disk herniation. AJNR Am J Neuroradiol. 2003;24(5):996-1000.

18. Iliakis E, Valadakis V, Vynios DH, Tsiganos CP, Agapitos E. Rationalization of the activity of medical ozone on intervertebral disc-A histological and biochemical study. J Neuroradiol. 2001;14:23-30.

19. Oyarzún GMJ, Sánchez RSA, Dussaubat DN, Miller AME, González BS. Effect of copper sulphate on the lung damage induced by chronic intermittent exposure to ozone. Rev Med Chil. 2017;145(1):9-16.

20. Vanni D, Galzio R, Kazakova A, et al. Intraforaminal ozone therapy and particular side effects: preliminary results and early warning. Acta Neurochir (Wien). 2016;158(3):491-496.

21. Valacchi G, Bocci V. Studies on the biological effects of ozone: 11 . Release of factors from human endothelial cells. Mediators Inflamm. 2000;9(6):271-276.

\section{Journal of Pain Research}

\section{Publish your work in this journal}

The Journal of Pain Research is an international, peer reviewed, open access, online journal that welcomes laboratory and clinical findings in the fields of pain research and the prevention and management of pain. Original research, reviews, symposium reports, hypothesis formation and commentaries are all considered for publication.

\section{Dovepress}

The manuscript management system is completely online and includes a very quick and fair peer-review system, which is all easy to use. Visit http://www.dovepress.com/testimonials.php to read real quotes from published authors. 